\title{
APLIKASI VITAMIN E DALAM PAKAN: KEBUTUHAN DAN PERANAN UNTUK MENINGKATKAN REPRODUKSI, SISTEM IMUN, DAN KUALITAS DAGING PADA IKAN
}

\author{
Wahyu Pamungkas \\ Balai Penelitian Pemuliaan Ikan \\ Jl. Raya 2 Sukamandi, Subang 41256, Jawa Barat \\ E-mail: yhoe_pamungkas@yahoo.co.id
}

\begin{abstract}
ABSTRAK
Vitamin E merupakan salah satu mikronutrien yang sangat diperlukan dalam pakan ikan dan berperan penting dalam proses pertumbuhan, reproduksi, kesehatan atau sistem imun, dan kualitas daging ikan. Vitamin E berfungsi sebagai pemelihara keseimbangan intraseluler dan sebagai antioksidan. Sebagai antioksidan, vitamin E dapat melindungi lemak atau asam lemak yang terdapat dalam membran sel agar tidak teroksidasi. Kebutuhan dasar vitamin E untuk ikan bervariasi, bergantung pada beberapa faktor yaitu ukuran ikan, umur ikan, suhu air, persentase pertumbuhan, dan komposisi pakan. Defisiensi vitamin E pada ikan akan menyebabkan muscular dystrophy, exudative diathesis, hematokrit rendah, depigmentasi kulit, penurunan laju pertumbuhan, dan lain-lain. Hipervitaminosis vitamin E dapat menyebabkan laju pertumbuhan yang rendah, reaksi keracunan pada organ hati dan kematian. Tujuan dari penulisan makalah adalah untuk memberikan informasi kebutuhan dan peranan vitamin $\mathrm{E}$ dalam pakan untuk meningkatkan reproduksi, sistem imun, dan kualitas daging pada ikan.
\end{abstract}

\section{KATA KUNCI : kualitas daging ikan, sistem imun, reproduksi, vitamin E}

\section{PENDAHULUAN}

Pakan merupakan salah satu faktor penentu keberhasilan usaha budidaya dan berperan penting dalam meningkatkan produksinya. Pakan yang berkualitas adalah pakan dengan nilai nutrisi yang seimbang dan sesuai dengan kebutuhan ikan. Pakan sangat diperlukan dalam suatu usaha budidaya karena setiap jenis ikan mempunyai persyaratan nutrisi yang berbeda untuk dapat tumbuh dan berkembang biak dengan baik, serta dalam mempertahankan sintasannya. Salah satu nutrisi dalam pakan yang dibutuhkan oleh ikan adalah vitamin. De Silva et al. (1995) menyatakan bahwa vitamin merupakan senyawa organik yang berperan sebagai kofaktor pada beberapa reaksi metabolik. Sebagai salah satu mikronutrien yang dibutuhkan dalam pakan, vitamin dibutuhkan dalam jumlah yang relatif sedikit namun mempunyai peran yang cukup besar dalam pertumbuhan dan sintasan ikan.

Salah satu vitamin yang dibutuhkan dalam pakan ikan adalah vitamin E ( $\alpha$-tocopherol). Vitamin E merupakan salah satu mikronutrien yang sangat diperlukan dan berperan penting dalam proses pertumbuhan, reproduksi, dan kesehatan ikan (Hunt et al., 2004). Menurut Alava et al. (1993), vitamin E berfungsi sebagai pemelihara keseimbangan intraseluler dan sebagai antioksidan. Lebih lanjut dinyatakan bahwa sebagai antioksidan, vitamin E dapat melindungi lemak atau asam lemak yang terdapat dalam membran sel agar tidak teroksidasi. Gammanpila et al. (2007) menyatakan bahwa vitamin E adalah salah satu mikronutiren penting yang berpengaruh terhadap performa reproduksi ikan. Vitamin E dalam pakan dapat meningkatkan keberhasilan pemijahan, fekunditas dan daya tetas telur, sintasan larva, indeks gonad somatic, serta vitelogenesis. Watanabe (1985) menunjukkan bahwa setelah pemijahan, terdapat kandungan vitamin E yang tinggi pada telur induk ikan dan rendah pada jaringan. Hal tersebut diduga adanya beberapa fungsi atau peran vitamin secara fisiologi pada proses pemijahan, fertilisasi, dan penetasan.

Vitamin E juga merupakan salah satu jenis vitamin yang mempunyai peran penting dalam pengaturan sistem imun 


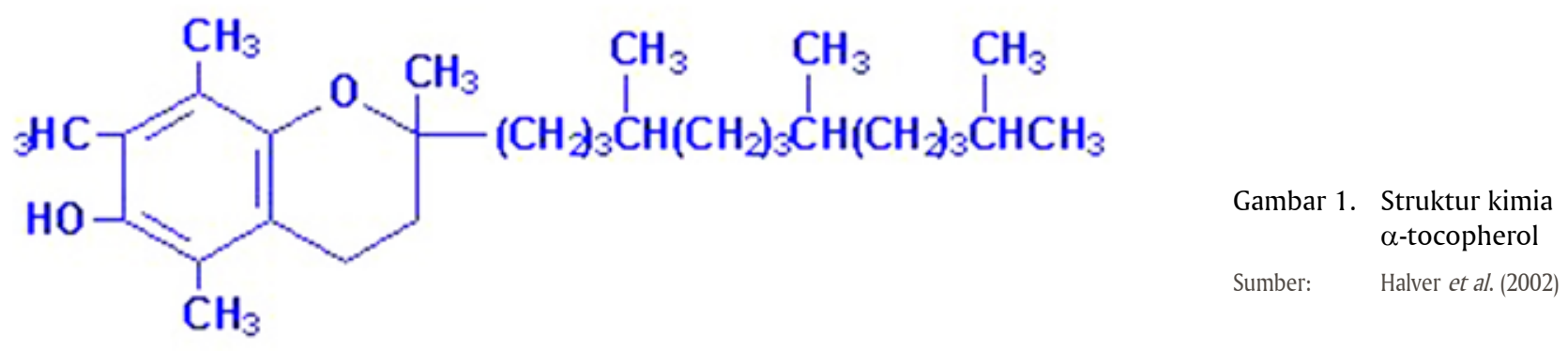

pada ikan dan dapat digunakan sebagai imunostimulan pada ikan yang dibudidaya. Menurut Putnam \& Comben (1987), vitamin E berperan penting dalam respons imun pada ikan, sebagai komponen penting pada membran sel dan mempunyai peran spesifik sebagai antioksidan. Blazer \& Wolke (1984) melaporkan bahwa defisiensi vitamin E dalam pakan yang diberikan pada ikan rainbow trout menurunkan sistem imun dan respons imun nonspesifik terhadap infeksi. Selain itu, vitamin E juga berperan dalam menjaga kualitas daging pada ikan. Adanya vitamin E akan mengurangi oksidasi lemak sehingga tidak terjadi degradasi pada daging ikan (Jensen et al., 1998).

Penambahan vitamin E dalam pakan dengan jumlah yang sesuai kebutuhan pada setiap jenis ikan akan meningkatkan performa reproduksi, sistem imun, dan kualitas daging pada ikan yang dibudidayakan. Dalam tulisan ini akan diuraikan mengenai kebutuhan, peranan dan pengaruh defisiensi vitamin E dalam pakan terhadap performa reproduksi, sistem imun, dan kualitas daging pada ikan. Tujuan dari penulisan makalah adalah memberikan informasi kebutuhan dan peranan vitamin E dalam pakan untuk meningkatkan reproduksi, sistem imun, dan kualitas daging pada ikan.

\section{Kebutuhan Vitamin E dalam Pakan}

Vitamin E dibutuhkan dalam jumlah yang berbeda pada ikan bergantung dari spesies, ukuran, laju pertumbuhan, hubungan antar nutrien, lingkungan (suhu dan bahan pencemar), serta fungsi metabolit (pertumbuhan, respons stres, ketahanan terhadap penyakit). Pada prakteknya, dosis vitamin pada pakan buatan dinaikkan sebesar 25\%-100\% dari kebutuhan dasar ikan untuk mengantisipasi kehilangan vitamin pada proses produksi, serta penyimpanan (Nasrulloh, 2006).
Vitamin E diketahui mengandung tocopherol dan turunan-turunannya, yang memiliki rantai jenuh atau tocoptrienol yang terdiri atas tiga ikatan karbon yang tidak jenuh. Salah satu yang terpenting dari tocopherol adalah $\alpha$-tocopherol dengan rumus kimia C23H50O2. Tocopherol stabil terhadap panas dan asam kuat dalam kondisi tidak ada oksigen (Halver et al., 2002). Tocopherol alami terkandung pada minyak nabati misalnya minyak kedelai, minyak kecambah biji kapas, minyak kecambah gandum, serta minyak kecambah biji-bijian yang lain. Tocopherol berperan sebagai inter dan ekstraselular antioksidan, untuk menjaga homeostatis pada metabolisme sel dan jaringan-jaringan. Sebagai antioksidan fisiologis, tocopherol berperan untuk melindungi vitamin-vitamin dan asam lemak tidak jenuh dari proses oksidasi.

Fungsi yang paling nyata dari vitamin E adalah sebagai antioksidan, terutama untuk melindungi asam lemak tidak jenuh pada fosfolipid dalam membran sel. Vitamin E diangkut ke hati dalam bentuk kilomikron, dari hati dan seterusnya, distribusinya mengikuti trigliserida dan lipid lainnya melalui lipoprotein ke jaringan lemak dan membran intra sel maupun ekstra sel. Peranan vitamin E sebagai antioksidan berhubungan erat dengan unsur mineral selenium dan enzim glutation peroksidase (Lehninger, 2003).

Kebutuhan dasar vitamin E untuk ikan bervariasi, bergantung pada beberapa faktor yaitu ukuran ikan, umur ikan, suhu air, persentase pertumbuhan, dan komposisi pakan. Gatlin et al. (1992) menyatakan bahwa untuk jenisjenis ikan catfish kebutuhan vitamin E berkisar antara 60$240 \mathrm{mg} / \mathrm{kg}$ ransum ikan. Sedangkan untuk jenis salmonid membutuhkan vitamin E $35 \mathrm{mg} / \mathrm{kg}$ hingga $300 \mathrm{mg} / \mathrm{kg}$ pakan. Jenis ikan channel catfish kebutuhan vitamin E dalam pakan $50 \mathrm{IU} / \mathrm{kg}$ pakan, sedangkan untuk jenis ikan salmonids adalah $30 \mathrm{IU} / \mathrm{kg}$ pakan. Satu International Unit (IU) vitamin E setara 
dengan $1 \mathrm{mg} \alpha$-tocopherol.Vitamin E dan asam lemak esensial dibutuhkan secara bersamaan untuk pematangan gonad ikan, dan dosis vitamin E di dalam pakan akan bergantung kepada kandungan asam lemak esensial yang ada di dalam pakan tersebut. Semakin tinggi kandungan asam lemaknya, maka kebutuhan vitamin E juga semakin tinggi (Watanabe et al. 1991). Hal tersebut juga dinyatakan oleh De Silva et al. (1995) bahwa tingginya kandungan asam lemak akan meningkatkan kebutuhan vitamin E dalam pakan. Lebih lanjut dinyatakan bahwa terdapat interaksi antara vitamin $\mathrm{E}$ dan selenium di mana kebutuhan vitamin $\mathrm{E}$ akan lebih tinggi pada ikan yang kekurangan selenium.

\section{Metabolisme Vitamin E}

Absorbsi vitamin E berhubungan dengan pencernaan lemak, dipermudah dengan adanya empedu dan lipase pankreas. Usus halus merupakan tempat utama absorbsi vitamin E dalam bentuk alkohol bebas maupun ester, sebagian besar vitamin E diabsorbsi sebagai alkohol. Alkohol memasuki usus dan ditranspor ke seluruh sirkulasi darah melalui kelenjar getah bening. Aktivitas terbesar vitamin E pada plasma dan jaringan hewan dalam bentuk $\alpha$-tocopherol. Tocopherol masuk ke dalam sistem resirkulasi, menyebar ke seluruh tubuh dan penyimpanan terbesar berada pada jaringan lemak. Vitamin E disimpan di dalam seluruh jaringan tubuh, terutama disimpan di jaringan adipose, hati, dan otot, penyimpanan terbesar berada pada hati. Sejumlah kecil vitamin E akan tersimpan di dalam tubuh dalam waktu yang lama. Jalur ekskresi utama dari absorbsi vitamin E adalah empedu. Biasanya, kurang dari $1 \%$ konsumsi akan diekskresikan melalui urine (McDowel, 2000).

Seperti halnya vitamin larut dalam lemak lainnya, penyerapannya membutuhkan lemak dalam pakan dan aktivitas asam empedu. Asam empedu berfungsi untuk merubah lemak menjadi emulsi lemak dengan cara membentuk komplek asam lemak-asam empedu, sehingga lebih mudah dicerna oleh enzim lipase sebelum diabsorbsi oleh dinding usus. Selanjutnya dikemukakan lagi bahwa vitamin $\mathrm{A}, \mathrm{D}, \mathrm{E}$, dan $\mathrm{K}$ (vitamin yang larut di dalam lemak) menjadi lebih mudah diserap oleh mukosa usus dengan adanya asam empedu.
Asam lemak tidak jenuh ganda (PUFA/Poly Unsaturated Fatty Acid), dapat menurunkan penyerapan dan penggunaan vitamin E. Hal ini berkaitan kemungkinan dengan kecenderungan vitamin E bersifat mudah teroksidasi. Oleh karena itu, kebutuhan vitamin E akan bertambah seiring dengan semakin bertambahnya konsumsi PUFA. Dengan demikian, peningkatan konsumsi PUFA yang tidak diikuti dengan peningkatan asupan vitamin E akan menimbulkan penurunan secara gradual $\alpha$-tocopherol dalam plasma.

\section{Peranan Vitamin E dalam Meningkatkan Performa Reproduksi}

Takeuchi et al. (1988) menguji efek kontribusi vitamin E pada badan ikan, pemijahan, penetasan telur, dan kematian benih. Didapatkan hasil bahwa pada induk yang diberi pakan dengan kadar vitamin yang rendah tidak memijah, sedangkan yang diberi pakan dengan kadar vitamin E yang lebih tinggi memijah. Vitamin E juga berfungsi untuk mendukung peran enzim sitokrom P450 mensintesis kolesterol untuk pembentukan hormon reproduksi, dalam hal ini $17 \alpha$-estradiol. Hormon $17 \alpha$-estradiol menstimulasi sintesis vitelogenin di hati. Pentingnya peranan vitamin E untuk reproduksi juga ditemukan pada beberapa jenis ikan, seperti carp, rainbow trout, dan read seabream. Umumnya konsentrasi vitamin E dalam telur tinggi dan konsentrasi vitamin E rendah pada jaringan tubuh induk setelah pemijahan, sehingga diduga beberapa fungsi fisiologi terkait dengan vitamin E pada saat pemijahan, pembuahan, dan penetasan telur.

Pada masa reproduksi, $\alpha$-tocopherol akan didistribusi ke jaringan adipose oosit. Sebelum sampai ke jaringan tersebut, $\alpha$-tocopherol bersama asam lemak berantai panjang yang berbentuk micelles terlebih dahulu diabsorbsi pada segmen usus (Machlin, 1990). Selanjutnya oleh enterocyte dalam bentuk gabungan kilomikron ( $\alpha$-tocopherol dengan mono, di dan trglycerida), vitamin tersebut dibawa ke saluran limpatik. Dari sistem limpatik $\alpha$-tocopherol bersama VLDL (Very Low Density Lipoprotein) akan masuk ke dalam sirkulasi darah. Pada sistem sirkulasi vena $\alpha$-tocopherol langsung dikirim sebagian ke bagian yang membutuhkan. Sebagian lagi terlebih dahulu masuk ke hati melalui ductus toracicus dan bergabung dengan VLDL yang 
kaya akan trigliserida dan HDL (High Density Lipoprotein) yang kaya akan fosfolipid, kolesterol, dan ester. Lebih lanjut dinyatakan bahwa VLDL dan HDL ini disintesa oleh hati.

Padaikan atlantiksalmon diketahui bahwa $\alpha$-tocopherol diangkut dari jaringan periferal ke gonad melalui hati bersama lipoprotein plasma, hal ini menunjukkan adanya peran vitamin E pada proses reproduksi ikan. Vitamin E diangkut ke hati dalam bentuk kilomikron, dari hati dan seterusnya, distribusinya mengikuti trigliserida dan lipid lainnya melalui lipoprotein ke jaringan lemak dan membran intra sel maupun ekstra sel. Selama vitelogenesis, kadar vitamin E dalam tubuh menurun sampai kira-kira 10\% hingga tingkat pematangan. Seperti halnya vitamin larut dalam lemak lainnya, penyerapannya membutuhkan lemak dalam pakan, dan aktivitas asam empedu. Asam empedu berfungsi untuk merubah lemak menjadi emulsi lemak dengan cara membentuk kompleks asam lemak-asam empedu, sehingga lebih mudah dicerna oleh enzim lipase sebelum diabsorbsi oleh dinding usus. Vitamin A, D, E, dan K (vitamin yang larut di dalam lemak) menjadi lebih mudah diserap oleh mukosa usus dengan adanya asam empedu.

Defisiensi $\alpha$-tocopherol pada hewan dapat menyebabkan lemah otot, pertumbuhan terhambat, degenerasi embrio, tingkat penetasan telur yang rendah, degenerasi dan pelepasan sel epitel germinatif dari testis dan terjadinya kemandulan, menurunkan produksi prostaglandin oleh mikrosom dari testis, otot dan limpa, menurunkan permeabilitas sel, memacu kematian, dan kerusakan syaraf (Lehninger, 2003). Kadar vitamin E pada telur dari ikan yellow tail yang terbaik adalah 186,6-243,0 $\mu \mathrm{g} / \mathrm{g}$ bobot kering telur. Kadar vitamin $\mathrm{E}$ dalam telur tersebut berasal dari induk yang mendapatkan pakan yang mengandung vitamin E 124,1-471,8 mg/kg pakan. Vitamin ini juga dapat memengaruhi komponen kimia lipid telur dan daya apung telur yellow tail.

Kebutuhan ikan terhadap vitamin E dalam ransum berbeda-beda bergantung kepada jenis dan umur ikan. Gatlin et al. (1992) menyatakan bahwa untuk jenis-jenis ikan catfish kebutuhan vitamin E berkisar antara $60-240 \mathrm{mg} / \mathrm{kg}$ ransum ikan. Sedangkan untuk jenis salmonid membutuhkan vitamin E $35 \mathrm{mg} / \mathrm{kg}$ hingga $300 \mathrm{mg} / \mathrm{kg}$ pakan. Vitamin E dan asam lemak esensial dibutuhkan secara bersamaan untuk pematangan gonad ikan, dan dosis vitamin E di dalam pakan akan bergantung kepada kandungan asam lemak esensial yang ada di dalam pakan tersebut. Semakin tinggi kandungan asam lemaknya, maka kebutuhan vitamin E juga semakin tinggi (Watanabe et al., 1991).

\section{Peranan Vitamin E Terhadap Sistem Imun}

Vitamin E merupakan salah satu nutrien terpenting yang berpengaruh terhadap sistem imun pada ikan dan suplai vitamin E dapat mengurangi mortalitas dan meningkatkan performa ikan dengan meningkatnya respons imun spesifik dan nonspesifik. Vitamin E juga merupakan antioksidan yang berperan dalam mengatasi kerusakan oksidatif jaringan pada ikan, meningkatkan resistensi membran sel darah merah dan mempertahankan fungsi leukosit (Kiron et al., 2004). Putnam \& Comben (1987) menyatakan bahwa vitamin E mempunyai peranan penting pada respons imun ikan yang merupakan komponen penting pada membran sel dan mempunyai peran spesifik sebagai antioksidan yang mengontrol peroksidasi asam lemak tak jenuh. Kekurangan vitamin E dalam pakan dilaporkan dapat mengurangi fagositosis makrofag dan fungsi limposit $\mathrm{T}$ dan B pada ikan rainbow trout dalam melawan Yersinia ruckeri, mengurangi aktivitas komplemen pada ikan Atlantik salmon, Salmo salar, merusak respons antibodi pada rainbow trout dan mengurangi aktivitas komplemen pada ikan Sparus aurata.

Vitamin E dilaporkan dapat meningkatkan respons imun spesifik pada ikan dan menjaga kualitas daging, resistensi korpus darah merah untuk hemolisis, dan permeabilitas kapiler, meskipun mekanismenya belum dapat digambarkan secara pasti (Halver, 2002). Beberapa studi melaporkan bahwa peningkatan respons imun, performa pertumbuhan, performa reproduksi, kecernaan nutrien, kualitas daging, dan resistensi terhadap penyakit pada berbagai spesies ikan setara dengan hewan terestrial melalui pemberian pakan dengan level vitamin E lebih tinggi dari yang dibutuhkan (Lee et al., 2003).

\section{Peranan Vitamin E dalam Meningkatkan Kualitas Daging}

Pada kegiatan budidaya perikanan, lemak dalam pakan yang diberikan adalah pakan yang mengadung asam lemak tak jenuh rantai ganda, dan asam lemak tersebut akan masuk 
dalam fillet ikan. Peningkatan kandungan lemak dalam pakan akan berpengaruh negatif terhadap kualitas ikan karena adanya degradasi pada fillet ikan melalui oksidasi lemak. Oleh karena itu, pakan seharusnya ditambahkan dengan antioksidan dalam jumlah yang mencukupi (Jensen et al., 1998).

Alfa tocopherol asetat digunakan sebagai sumber vitamin E dalam pakan pada kegiatan budidaya dengan tujuan meningkatkan pertumbuhan ikan (Huo et al., 1999). Pengaruh dari vitamin E dalam berbagai jumlah dalam pakan terhadap kualitas daging ikan telah banyak dipelajari untuk berbagai spesies ikan seperti rainbow trout (Jensen et al., 1998), sea bass (Gatta et al., 2000), Atlantic salmon, turbot (Ruff et al., 2003), catfish (Ng et al., 2003), dan hybrid tilapia (Huang et al., 2003). Hasil penelitian sebelumnya menunjukkan bahwa terdapat korelasi positif antara pakan yang mengandung vitamin $\mathrm{E}$ dengan kandungan vitamin $\mathrm{E}$ dalam daging ikan. Hasil penelitian Yildiz (2004), menyatakan bahwa ikan yang diberikan pakan dengan kandungan alfa tocopherol asetat lebih dari 370,5 mg/kilogram pakan menghasilkan kualitas daging ikan yang lebih baik.

\section{Defisiensi Vitamin E dalam Pakan Ikan}

Kebutuhan dasar vitamin E untuk ikan bervariasi, bergantung pada beberapa faktor yaitu ukuran ikan, umur ikan, suhu air, persentase pertumbuhan, dan komposisi pakan. Jenis ikan channel catfish membutuhkan vitamin E 50 IU/kg pakan, sedangkan untuk jenis ikan salmonids adalah $30 \mathrm{IU} / \mathrm{kg}$ pakan. Satu International Unit (IU) vitamin E setara dengan $1 \mathrm{mg} \_\alpha$-tocopherol. Gejala defisiensi vitamin E pada ikan antara lain muscular dystrophy, exudative diathesis, hematokrit rendah, depigmentasi kulit, penurunan laju pertumbuhan, dan lain-lain. Hipervitaminosis vitamin E dapat menyebabkan laju pertumbuhan yang rendah, reaksi keracunan pada organ hati, dan kematian (Halver, 2002).

Lehninger (2003) menyatakan bahwa defisiensi $\alpha$-tocopherol pada hewan dapat menyebabkan lemah otot, pertumbuhan terhambat, degenerasi embrio, tingkat penetasan telur yang rendah, degenerasi pelepasan sel epitel germinatif dari testis, otot, dan limfa, menurunkan permeabilitas sel, memacu kematian, dan kerusakan syaraf.

Penelitian ikan atlantik salmon Salmo salar, dengan bobot lebih kurang 16,9 g; diberi pakan dasar semi murni yang mengandung kasein dan alfa tocopherol asetat 0 dan15 mg/kg pakan, menyebabkan tingkat kematiannya $100 \%$ dan jika diberi $30 \mathrm{mg} / \mathrm{kg}$ pakan, ikan akan mengalami gejala defisiensi. Ikan yang mengalami defisiensi vitamin $\mathrm{E}$ memperlihatkan kandungan haemoglobin darah rendah, volume dan jumlah sel darah merah meningkat, dan bagian sel darah merah tidak matang. Kadar vitamin E $60 \mathrm{mg} / \mathrm{kg}$ pakan dapat memberikan sintasan ikan yang tinggi. Kadar vitamin E di telur pada ikan yellow tail yang terbaik adalah 186,6-243,0 $\mu \mathrm{g} / \mathrm{g}$ bobot kering telur. Kadar vitamin E dalam telur tersebut berasal dari induk yang mendapatkan pakan yang mengandung vitamin E 124,1-471,8 mg/kg pakan. Vitamin ini juga dapat memengaruhi komponen kimia lipid telur dan daya apung telur yellow tail.

\section{PENUTUP}

Vitamin E sebagai salah satu mikronutrien dalam pakan diperlukan keberadaannya dalam pakan ikan untuk meningkatkan pertumbuhan, reproduksi, kesehatan, dan kualitas daging ikan. Kebutuhan dasar vitamin E pada ikan bergantung pada jenis, ukuran dan umur ikan, suhu air, persentase pertumbuhan, dan komposisi pakan. Kelebihan dan kekurangan vitamin E dalam pakan dapat mengakibatkan penurunan laju pertumbuhan, timbulnya penyakit, keracunan, dan kematian.

\section{DAFTAR ACUAN}

Alava, V.R., Kanazawa, A., Thesima, S., \& Koshio, S. 1993. Effects of dietary vitamin A, E, and C on the ovarian development of Penaeus japonicus. Nippon Suisan Gakkaishi, 59(7): 1,235-1,241.

Blazer, V.S. \& Wolke, R.E. 1984. The effects of atocopherol on the immune response and non-specific resistance factors of rainbow trout (Salmo gairdneri Richardson). Aquaculture, 37: 1-9.

De Silva, S.S. \& Anderson, T.A. 1995. Fish Nutrition in Aquaculture. $1^{\text {st }}$ Edition. Chapman and Hall, Aquaculture Series 1 London. ISBN:0-412-55030-X. p. 319.

Gammanpila, M., Yakupitiyage, A., \& Bart, A.N. 2007. Evaluation of the effects of dietary vitamin C, E and zinc supplementation on reproductive performance of Nile tilapia (Oreochromis niloticus). Aquaculture Science, 
12: 39-60.

Gatta, P.P., Pirini, M., Testi, S., Vignola, G., \& Monetti, P.G. 2000. The influence of different levels of dietary vitamin E on sea bass Dicentrarchus labrax flesh quality. Aquaculture Nutrition, 6: 47-52.

Gatlin, D.M., Bai, S.C., \& Erickson, M.C. 1992. Effect of dietary vitamin $\mathrm{E}$ and synthetic antioxidants on composition and storage quality of channel catfish, Ictalurus punctatus. Aquaculture, 106: 323-332.

Halver, J.E. 2002. The vitamins. In Halver, J.E. \& Hardy, R.W. (Eds). Fish Nutrition. $3^{\text {rd }}$ Edition. Academic Press, San Diego CA, USA. p. 61-141.

Huang, C.H., Chang, R.J., Huang, S.L., \& Chen, W. 2003. Dietary vitamin E supplementation affects tissue lipid peroxidation of hybrid tilapia, Oreochromis niloticus X 0. aureus. Comp. Biochem. and Physiol., Part B, 134: 265-270.

Hunt, A.O., Ozkan, F., \& Altun, T. 2004. Effect of broodstock nutrition on reproductive performance of fish. Turk. Journal Aquatic. Life., 2(3): 487-493.

Huo, J.Z., Nelis, H.J., Lavens, P., Sorgeloos, P., \& De Leenheer, A.P. 1999. Simultaneous determination of $\alpha$-tocopheryl acetate and tocopherols in aquatic organisms and fish feed. Journal of Chromatography B, 724: 249-255.

Jensen, C., Birk, E., Jokumsen, A., Skibsted, L.H., \& Bertelsen, G. 1998. Effect of dietary levels of fat, $\alpha$-tocopherol and astaxanthin on colour and lipid oxidation during storage of frozen rainbow trout (Oncorhynchus mykiss) and during chill storage of smoked trout. Zeitschrift für Lebensmittel Unters. Forsch. A, 207: 189-196.

Kiron, V., Puangkaew, J., Ishizaka, K., Satoh, S., \& Watanabe, T. 2004. Antioxidant status and nonspecific immune responses in rainbow trout (Oncorhynchus mykiss) fed two levels of vitamin $\mathrm{E}$ along with, three lipid sources. Aquaculture, 234: 361-379.

Lee, S.K., Kim, Y.S., Liang, C.Y., \& Song, Y.H. 2003. Effects of dietary vitamin E supplementation on color stability, lipid oxidation and reducing ability of Hanwoo (Korean cattle) beef during retail display. Asian-Aust. J. Anim. Sci., 16: 1,529-1,534.
Lehninger, L.A. 2003. Dasar-dasar biokimia. Jilid I. Penerbit Erlangga. Jakarta, $368 \mathrm{hlm}$.

Machlin, L.J. 1990. Handbook of vitamins. 2nd Ed. Marcel Dekker New York, p. 272-288.

McDowell, L.R. 2000. Vitamin in animal nutrition. Academic Press. Tokyo.

Mustafa, Y. 2004. The study of fillet quality and the growth performance of rainbow trout (Oncorhynchus mykiss) fed with diets containing different amounts of vitamin E. Turkish Journal of Fisheries and Aquatic Sciences, 4: 8186.

Nasrulloh, A.F. 2006. Perkembangan sperma ikan zebra (Brachydanio rerio) yang diberi pakan dengan berbagai dosis vitamin E. Skripsi. Institut Pertanian Bogor, 43 hlm.

Ng, W.K., Lim, P.K., \& Boey, P.L. 2003. Dietary lipid and palm oil source affects growth, fatty acid composition and muscle $\alpha$-tocopherol concentration of African catfish, Clarias gariepinus. Aquaculture, 215: 229-243.

Putnam, M.E. \& Comben, N. 1987. Vitamin E. Veterinary Record, 121: 541-545.

Ruff, N., FitzGerald, R.D., Cross, T.F., Hamre, K., \& Kerry, J.P. 2003. The effect of dietary vitamin $E$ and $C$ level on market-size turbot (Scophthalmus maximus) fillet quality. Aquaculture Nutrition, 9: 91-103.

Takeuchi, T. 1988. Laboratory work. Chemical evaluation of dietary nutrients. In Fish nutrition and mariculture. JICA textbook, the general aquaculture course. Watanabe, T. (Ed.). Japan International Cooperation Agency, p. 179-233. Watanabe, T., Koizumi, T., Suzuki, H., Satoh, S., Takeuchi, T., Yoshida, N., Kitada, T., \& Tsukashima, Y. 1985. Improvement of quality of red sea bream eggs by feeding broodstock on a diet containing cuttlefish meal or raw krill shortly before spawning. Nippon Suisan Gakkaishi, 51(9): 1,511-1,521.

Watanabe, T., Fujimura, T., Lee, M.J., Fukusho, K., Satoh, S., \& Takeuchi, T. 1991. Effect of polar and non polar lipids from krill on quality of eggs of red seabream Pagrus major. Nippon Suisan Gakkaishi, 57(4): 695-698. 